ESTUDIOS 



\title{
LAS SOCIEDADES MERCANTILES PÚBLICAS. SU NATURALEZA JURÍDICA PRIVADA Y SU PERSONALIDAD JURÍDICA DIFERENCIADA: ¿̇REALIDAD O FICCIÓN?
}

\author{
CARMEN CHINCHILLA MARÍN ${ }^{1}$ \\ Universidad de Alcalá
}

Cómo citar/Citation

Chinchilla Marín, C. (2017).

Las sociedades mercantiles públicas. Su naturaleza jurídica privada y su personalidad jurídica diferenciada: Żrealidad o ficción?

Revista de Administración Pública, 203, 17-56. doi: https://doi.org/10.18042/cepc/rap.203.01

Resumen

Este artículo tiene por objeto reflexionar sobre las sociedades mercantiles públicas, desde una doble perspectiva. En primer lugar, la de si, a pesar de su naturaleza privada, se rigen, realmente, por el derecho privado. $Y$, en segundo lugar, si su personalidad jurídica es, verdaderamente, una personalidad propia y diferenciada de la de la Administración matriz. La falta de rigor y coherencia en la regulación de estas entidades plantea, en la práctica, numerosos problemas, entre los que destaca el de la posible responsabilidad subsidiaria de la Administración matriz por las deudas de sus sociedades.

\section{Palabras clave}

Sociedades mercantiles públicas; derecho aplicable; significado de la personalidad jurídica; responsabilidad de la Administración matriz.

1 Catedrática de Derecho Administrativo. 


\section{Abstract}

The purpose of this article is to analyze public companies from a dual perspective. Firstly, although being private entities, whether or not they are actually governed by private law and, secondly, if their legal personality is truly their own and separate from that of the parent Administration. The lack of consistency and coherence in the regulations governing these entities gives rise to numerous practical problems, particularly including that of the possible vicarious liability of the parent Administration for public company debts.

\section{Keywords}

Public companies; governing law; meaning of legal personality; liability of the parent Administration. 


\section{SUMARIO}

I. PLANTEAMIENTO. II. CARACTERÍSTICAS GENERALES DE LAS SOCIEDADES MERCANTILES PÚBLICAS. III. EL RÉGIMEN JURÍDICO-ADMINISTRATIVO AL QUE ESTÁN SOMETIDAS LAS SOCIEDADES MERCANTILES PÚBLICAS: 1. Procedimiento Y régimen de los actos administrativos. 2. Contratación pública. 3. Bienes públicos. 4. Empleo público. 5. Responsabilidad extracontractual. IV. LA PERSONALIDAD JURÍDICA DE LAS SOCIEDADES MERCANTILES PÚBLICAS: ¿̇REALIDAD O FICCIÓN? 1. La búsqueda de la respuesta en los pronunciamientos del Tribunal Constitucional y del Tribunal Supremo. 2. La búsqueda de la respuesta en la legislación administrativa. V. REFLEXIÓN FINAL, A LA LUZ DE TODO LO EXPUESTO, ACERCA DE UNA CUESTIÓN PRÁCTICA: ¿̇DEBE O NO RESPONDER LA ADMINISTRACIÓN MATRIZ POR LAS DEUDAS DE SUS SOCIEDADES MERCANTILES?: 1. Resumen de los pronunciamientos de la jurisprudencia civil y contencioso-administrativa sobre la cuestión. 2. Una propuesta de solución al problema planteado.

\section{PLANTEAMIENTO}

No puede ponerse en duda la importancia que las formas tienen en y para el derecho, pero también es sabido que, en derecho, se busca la realidad y la sustancia por encima de las formas, cuando dicha sustancia y realidad no responden a las características y elementos que las forman definen. Baste recordar ese principio, repetido en tantas sentencias de nuestros tribunales, según el cual «en derecho, las cosas son lo que son y no lo que se dicen que son» o «lo que se las llame» ${ }^{2}$. Es decir que, por encima del nomen iuris, hay que buscar la realidad y la sustancia que lo habita, esto es, su sustrato real.

2 Es tan reiterada la invocación de este principio en las sentencias de los tribunales, de todos los órdenes jurisdiccionales, que no sería necesaria su cita. En cualquier caso, y a título de ejemplo, baste citar las SSTS, Sala de lo Contencioso-Administrativo, 
El objeto de este trabajo es reflexionar sobre la cuestión de si, en el caso de las sociedades mercantiles públicas, la forma de personificación es realmente determinante, y determinante de qué exactamente. Y, más concretamente, reflexionar sobre (i) si las sociedades mercantiles públicas se rigen, como corresponde a su forma jurídico-privada, por el derecho privado y (ii) si su personalidad jurídica es, verdaderamente, una personalidad jurídica distinta, diferenciada e independiente de la persona jurídica que es la Administración pública titular de sus acciones.

Sin perjuicio de que a lo largo de las páginas que siguen pueda referirme a este tipo de entidades usando, indistintamente, términos como sociedades mercantiles estatales, sociedades mercantiles públicas o sociedades mercantiles del sector público, debo advertir que este trabajo no trata de las sociedades mercantiles públicas y de su régimen jurídico, en general, sino de las dos cuestiones concretas que acabo de enunciar. La limitación del número de páginas me ha llevado, además, a realizar el análisis de estas dos cuestiones tomando como referencia las sociedades públicas estatales, ya que, al no existir una regulación general sobre las sociedades mercantiles del sector público, la regulación de las sociedades públicas autonómicas y las locales se encuentra dispersa en numerosas normas sobre las más diversas materias (régimen jurídico del sector público, patrimonio, contratación, hacienda, régimen financiero y presupuestario, etc.) cuyo estudio es imposible abordar en un trabajo como este.

Dicho esto, el hecho de centrar el análisis en las sociedades estatales no significa que las reflexiones y eventuales conclusiones que aquí se alcancen respecto de estas no sean trasladables a las sociedades mercantiles autonómicas y locales, pues, en principio y con carácter general, lo son, ya que se trata, igualmente, de sociedades del sector público.

\section{CARACTERÍSTICAS GENERALES DE LAS SOCIEDADES MERCANTILES PÚBLICAS}

Como ya he adelantado, no existe en nuestro ordenamiento jurídico una regulación de las sociedades mercantiles públicas común para todo el sector público ${ }^{3}$.

de 17 de septiembre de 2012, recurso 419/2010, y de 25 de mayo de 2016, recurso 4082/2014.

3 En mi opinión, hay razones para entender que el Estado podría tener competencias para legislar en esta materia, bien para definir las características esenciales de estas entidades, al amparo del título «bases del régimen jurídico de las Administraciones 
En la Ley 40/2015, que es la que regula el régimen jurídico del sector público del que forman parte las sociedades mercantiles públicas, los preceptos dedicados específicamente a las sociedades mercantiles solo resultan aplicables a las sociedades mercantiles estatales, siendo muy pocos y de carácter residual los artículos de esta ley que son básicos y, por consiguiente, de aplicación a todas las sociedades mercantiles públicas ${ }^{4}$. Igualmente, en la Ley 33/2003, del Patrimonio de las Administraciones públicas (LPAP), los únicos preceptos referentes a las sociedades mercantiles son de aplicación exclusiva a las mercantiles estatales.

De acuerdo con el art. 111. 1 de la Ley 40/205 del Régimen Jurídico del Sector Público (LRJSP), se entenderá por sociedades mercantiles estatales aquellas sobre las que se ejerce un control estatal, lo cual se puede producir en virtud de una de las dos circunstancias siguientes:

a) que la participación directa, en su capital social, de la Administración General del Estado o de alguna de las entidades que integran el sector público estatal ${ }^{5}$, incluidas las sociedades mercantiles estatales, sea superior

públicas» (148.1.18 CE), desde el momento en que son entes instrumentales y dependientes de dichas administraciones; bien para establecer una serie de normas sustantivas y específicas para estas sociedades que conformarían un derecho especial, distinto del derecho común de las sociedades mercantiles, y que podría encontrar cobertura en el título «legislación mercantil»(149.1.6 CE).

A propósito del título competencial del art. 149.1.18 CE, cabría argumentar, además, que no es razonable que el Estado pueda establecer una legislación básica sobre el patrimonio de las administraciones públicas, al amparo del título «bases del régimen jurídico de las Administraciones públicas» y, sin embargo, no pueda hacer lo mismo con la regulación de las sociedades mercantiles públicas, cuando en estas se da la doble circunstancia de que, por un lado, forman parte del patrimonio de la Administración titular de sus acciones (concretamente, del "patrimonio empresarial de la Administración General del Estado», según el título VIII de la Ley 33/2003, del Patrimonio de las Administraciones públicas) y, por otro, no dejan de ser, en el fondo, una técnica de organización administrativa.

4 Disposición final decimocuarta, apartado 2, de la Ley 40/2015: «No tiene carácter básico y se aplica exclusivamente a la Administración General del Estado y al sector público estatal lo previsto en [...] el Capítulo $\mathrm{V}$ de las sociedades mercantiles estatales». Son básicos y se refieren a las sociedades mercantiles o, genéricamente, a las entidades de derecho privado, los arts. 2.2.b); 3 (por remisión del 2.2.b); 35; 81 y 82.

5 De acuerdo con el art. 84.1 LRJSP, el sector público estatal está integrado por: a) los organismos públicos (organismos autónomos y entidades públicas empresariales); b) las autoridades administrativas independientes; c) las sociedades mercantiles estatales; 
al $50 \%$, siendo este un porcentaje que se determinará sumando las participaciones correspondientes a la Administración General del Estado y a todas las entidades integradas en el sector público institucional estatal, en el caso de que en el capital social participen varias de ellas.

b) Que la sociedad mercantil se encuentre en el supuesto previsto en el art. 5 de la Ley del Mercado de Valores (RDL 4/2015) respecto de la Administración General del Estado o de sus organismos públicos vinculados o dependientes, es decir, que la sociedad sea dependiente de la Administración estatal o de un organismo público suyo en los términos establecidos en el art. 42 del Código de comercio respecto de los grupos de sociedades.

Dentro de las sociedades mercantiles estatales, la LPAP, en su art. 166.2, distingue las que son de capital íntegramente público — de la Administración General del Estado o de sus organismos públicos- de las que solo son mayoritarias, estableciendo para las primeras un régimen de control por parte de la Administración u organismo titular de las acciones más intenso que para las segundas. Esa especial intensidad en el control se pone de manifiesto, por un lado, en que el Consejo de Ministros puede atribuir a un Ministerio, cuyas competencias guarden una relación específica con su objeto social, la tutela funcional de la misma. Y, por otro, en que el titular del Ministerio al que corresponda su tutela podrá dar instrucciones a las sociedades para que realicen determinadas actividades, cuando su ejecución resulte de interés público. En este caso, el art. 116 LRJSP prevé que si los administradores de la sociedad actuasen diligentemente en cumplimiento de las instrucciones del ministro, y de ello se derivasen consecuencias lesivas, quedarían exonerados de responsabilidad.

Como es lógico, la consecuencia más importante de la forma privada de personificación que adoptan estas entidades del sector público institucional es que se rigen por el ordenamiento jurídico privado. Sin embargo, ello es así solo parcialmente, pues lo cierto es que existe un derecho administrativo aplicable a estas sociedades que se aplica con preferencia al derecho privado, y que se encuentra fragmentado en varias leyes, como son, entre otras, la Ley de Régimen Jurídico del Sector público, la legislación de Régimen Local, la Ley del Patrimonio de las Administraciones públicas, la Ley General Presupuestaria, el Estatuto Básico del empleado público, la Ley de Contratos del sector público y la Ley de Estabilidad presupuestaria y sostenibilidad financiera. El

d) los consorcios; e) las fundaciones del sector público; f) los fondos sin personalidad jurídica; y g) las universidades públicas. 
tenor literal del art. 113 LRJSP lo pone claramente de manifiesto así al establecer que:

Las sociedades mercantiles estatales se regirán por lo previsto en esta Ley, por lo previsto en la Ley 33/2003, y por el ordenamiento jurídico privado, salvo en las materias en que le sea de aplicación la normativa presupuestaria, contable, de personal, de control económico-financiero y de contratación.

El problema de esta remisión —amplia e imprecisa - a las normas administrativas "que les sean de aplicación» es que, en la práctica, no siempre es fácil determinar qué normas, de todas las contenidas en esas leyes del ordenamiento jurídico administrativo, resultan de aplicación a las sociedades mercantiles, porque la Ley no habla de las normas que les resulten expresamente de aplicación, sino las que les resulten de aplicación, sin más; lo cual significa que les resultarán de aplicación las normas de derecho administrativo que así lo digan específicamente, y las que, no diciéndolo, haya que deducir que les resultan de aplicación. Con frecuencia, esta fórmula, según la cual las sociedades mercantiles se rigen por el derecho privado salvo en lo que, del derecho público, les resulte de aplicación, conduce a un espacio jurídico en el que reina la indefinición y, en el que, ante un problema concreto, no se sabe qué derecho hay que aplicar, con lo cual la huida del derecho administrativo que se produce con la actuación de las administraciones públicas a través de sociedades mercantiles termina convirtiéndose, simplemente, en una huida del derecho ${ }^{6}$.

El máximo exponente de esta singular configuración de unas personas jurídicas que son formalmente privadas, pero que se regulan, en gran parte, por el derecho público e, incluso, a veces, por el mismo derecho público que las administraciones públicas que son sus titulares, lo constituyen unas disposiciones incorporadas a nuestro ordenamiento jurídico recientemente, en las que se viene a reconocer que las sociedades mercantiles públicas pueden ejercer potestades $^{7}$. Y la consecuencia de ese extravagante reconocimiento, en una disposición legal, de lo que no es más que una anomalía, pues solo los poderes públicos

6 Con mayor detalle me he referido a ello en C. Chinchilla Marín (2016), «El derecho de la Unión Europea como freno a la huida del Derecho Administrativo", Revista de Administración Pública, 200, págs. 362-367.

7 El art. 2.1.b) de la Ley 39/2015, del Procedimiento Administrativo Común de las Administraciones Públicas, establece que dicha ley se aplica a «las entidades de derecho privado vinculadas o dependientes de las Administraciones públicas, que quedarán sujetas a lo dispuesto en las normas de esta Ley que específicamente se refieran a las mismas y, en todo caso, cuando ejerzan potestades administrativas». 
deberían poder ejercer potestades públicas, es, nada más y nada menos, que, cuando las sociedades mercantiles ejercen potestades administrativas les resulta de aplicación, «en todo caso», es decir, no solo cuando existen disposiciones específicamente referidas a ellas, sino, en general, la Ley de Procedimiento Administrativo común, esto es, la ley que regula los actos administrativos, con sus atributos de presunción de validez y ejecutividad; el procedimiento administrativo; los medios de ejecución forzosa de los actos administrativos; el silencio; los recursos administrativos, la revisión de oficio, etc.

Finalmente, debe destacarse una última característica de las sociedades mercantiles que también ha sido consagrada recientemente en nuestro ordenamiento jurídico y que responde a la necesidad de racionalizar y, por consiguiente, reducir el sector público. Por un lado, la LRJSP obliga a todas las administraciones públicas a disponer de un sistema de supervisión continua de sus entidades dependientes, incluidas, por tanto, las sociedades mercantiles, con el objeto de comprobar la subsistencia de los motivos que justificaron su creación y su sostenibilidad financiera. Además, establece la obligación de realizar una formulación periódica y expresa de propuesta de transformación, mantenimiento o extinción (art. 81.2 LRJSP). Por otro lado, y por lo que se refiere específicamente al sector público estatal y, en particular, a las sociedades mercantiles estatales, son destacables dos disposiciones de la Ley 40/2015 que tienen en común el hecho de imponer condiciones a la creación de este tipo de entidades. Por un lado, para que una entidad del sector público estatal pueda tener la consideración de "medio propio o servicio técnico» de la Administración, es necesario que, además de disponer de medios suficientes e idóneos para realizar prestaciones en el sector de actividad que se corresponda con su objeto social, se dé alguna de las circunstancias siguientes: a) que sea una opción más eficiente que la contratación pública y resulte sostenible y eficaz,

Por su parte, el art. 2.2.b) de la Ley 40/2015 (LRJSP) establece que «las entidades de derecho privado vinculadas o dependientes de las Administraciones públicas quedarán sujetas a lo dispuesto en las normas de esta Ley que específicamente se refieran a las mismas, en particular a los principios previstos en el art. 3, y en todo caso, cuando ejerzan potestades administrativas».

Asimismo, el art. 113 de la LRJSP, al definir cuál es el régimen jurídico de las sociedades mercantiles estatales, dice que «en ningún caso podrán disponer de facultades que impliquen el ejercicio de autoridad pública, sin perjuicio de que excepcionalmente la ley pueda atribuirle el ejercicio de potestades administrativas».

En sentido parecido, llama la atención que, en la reforma del art. 135 de la Constitución, la exposición de motivos utilice la expresión "poderes públicos» para designar a todos los entes del sector público, incluidos los de naturaleza privada, que quedan sujetos a los principios de estabilidad presupuestaria y sostenibilidad financiera. 
aplicando criterios de rentabilidad económica; y b) que resulte necesario por razones de seguridad pública o de urgencia en la necesidad de disponer de los bienes o servicios suministrados por el medio propio o servicio técnico (art. 86.2 LRJSP).

Por otro lado, y por lo que se refiere a las transformaciones de las entidades integrantes del sector público institucional estatal, la Ley trata de forma muy distinta el proceso de transformación cuando lo que se transforma es una sociedad mercantil en cualquier otra modalidad de ente institucional (organismo autónomo, entidad pública empresarial, etc.) que cuando es un organismo público (organismo autónomo o entidad pública empresarial) el que pasa a ser una sociedad mercantil. En el primer caso, basta un Real Decreto, en el que no debe justificarse nada, y la transformación tendrá lugar por cesión e integración global, en unidad de acto, de todo el activo y el pasivo de la entidad transformada con sucesión universal de derechos y obligaciones. En el segundo caso (transformación de un organismo público en sociedad mercantil), el Real Decreto deberá ir acompañado de una memoria que incluya: i) una justificación de la transformación por no poder asumir sus funciones manteniendo su naturaleza jurídica originaria; ii) un análisis de eficiencia que incluya una previsión del ahorro que generará la transformación y la acreditación de inexistencia de duplicidades con las funciones que ya desarrolle otro órgano, organismo público o entidad preexistente, y iii) un análisis de la situación en la que quedará el personal, indicando si, en su caso, parte del mismo se integrará bien en la Administración General del Estado o bien en la sociedad mercantil que resulte de la transformación. Además, la Intervención General del Estado tendrá que emitir un informe en el que valorará el cumplimiento de los requisitos establecidos en el art. 87 LRJSP.

\section{EL RÉGIMEN JURÍDICO-ADMINISTRATIVO AL QUE ESTÁN SOMETIDAS LAS SOCIEDADES MERCANTILES PÚBLICAS}

Como ya he dicho, a pesar de adoptar una forma de personificación privada (la de las sociedades de capital), las sociedades mercantiles públicas no se rigen $o$, mejor dicho, no se rigen solo, ni siquiera principalmente, por el derecho privado, sino que el legislador ha establecido para ellas numerosas normas, del más variado contenido, que vienen a poner en entredicho su naturaleza privada y que, en definitiva, demuestran que se trata de unas entidades que están a medio camino entre una Administración pública y una empresa privada, pues no siendo ni lo uno ni lo otro, tienen elementos característicos de ambas. 
Sin ánimo de ser exhaustiva ${ }^{8}$, a continuación expondré las disposiciones que recogen algunas de esas reglas que contienen un derecho especial y exorbitante del derecho común de las sociedades de capital y que resulta de aplicación a las sociedades mercantiles públicas.

\section{PROCEDIMIENTO Y RÉGIMEN DE LOS ACTOS ADMINISTRATIVOS}

En primer lugar, y como ya he adelantado, por muy anómalo y paradójico que resulte, las sociedades mercantiles pueden tener atribuidas potestades administrativas, en cuyo caso deberán regirse, en el ejercicio de esas potestades, por la Ley 39/2015 de Procedimiento Administrativo Común (LPAC). No especifica la Ley qué disposiciones de la misma les resultarán de aplicación, pero, tal y como está redactado su art. 2.2.b), cabría entender que se trata de una aplicación con vocación de generalidad, ya que, tras decir que las entidades privadas quedarán sujetas a las normas de la LPAC «que específicamente se refieran a las mismas», a continuación añade, como si se tratase de un supuesto diferente, y de alcance más general, que dicha ley se les aplicará, «en todo caso, cuando ejerzan potestades públicas». Teniendo en cuenta que las disposiciones específicas de esta ley, referidas a las sociedades mercantiles públicas, no existen como tales, lo lógico es pensar que lo que el legislador ha querido decir es que, si ejercen potestades administrativas, el ejercicio de dichas potestades ha de quedar sujeto a las normas que, con carácter general, regulan el procedimiento y la forma de producirse los actos administrativos, con sus atributos de presunción de validez y eficacia, con sus medios de ejecución forzosa, su régimen de invalidez, etc. Y no dejaría de tener sentido que así fuese, pues el ejercicio del poder tiene que sujetarse, necesariamente, a las reglas que el derecho administrativo ha creado para ello, en garantía de la consecución del interés general y de la protección de los derechos de los ciudadanos. Dicho lo cual, una sociedad mercantil no debería ejercer nunca potestades públicas, pues carece de sentido adoptar una forma jurídico-privada y que la ley le atribuya potestades públicas. Si la huida del derecho administrativo es una técnica criticable, no puede serlo menos la que consiste en crear una persona jurídica privada para, luego, atribuirle potestades públicas. Ahora bien, si se acepta que una sociedad mercantil puede ejercer potestades

8 Dejo, por ejemplo, al margen de mi estudio, la cuestión de la incidencia que, sobre el régimen concursal de las sociedades mercantiles públicas, tiene el art. 135 de la Constitución que declara la prioridad absoluta de los créditos para satisfacer los intereses y el capital de la deuda pública, precepto que resulta de aplicación a todas las entidades del sector público. 
administrativas, la consecuencia lógica y necesaria ha de ser que se rija por el derecho administrativo.

Así lo ha manifestado el Tribunal Supremo, mucho antes, por cierto, de que se aprobaran las Leyes 39 y 40 de 2015, al afirmar de forma natural, aunque no por ello menos sorprendente, que una sociedad mercantil pública, prestadora del servicio portuario de atraque de embarcaciones deportivas y que gestiona el dominio público portuario, ejerce "potestades administrativas que deben someterse y regirse por el Derecho administrativo, de manera que sus actos son actos administrativos revisables en vía administrativa y contencioso-administrativa»" No explica el Tribunal Supremo cuáles son esas potestades administrativas que ejerce la sociedad mercantil, ni tampoco qué norma se las ha atribuido, pues tratándose de potestades públicas debería haber una norma que se las atribuyera. Simplemente, el Tribunal Supremo se limita a afirmar que las tiene y concluye que, por eso, dicta actos administrativos; queda sujeta al derecho administrativo y, por consiguiente, a los recursos administrativos y al recurso contencioso-administrativo. Esto es, todo lo contrario al régimen jurídico que se corresponde con la forma de entidad privada propia de las sociedades mercantiles.

\section{CONTRATACIÓN PÚBLICA}

El derecho administrativo de la contratación, que desde hace años cambió la denominación de su ley de cabecera (de llamarse Ley de Contratos de las "Administraciones públicas» pasó a llamarse Ley de Contratos del «Sector público»), es uno de los mejores ejemplos de que las sociedades mercantiles públicas, a pesar de su forma de personificación privada, están sujetas al derecho administrativo. En efecto, esta Ley ${ }^{10}$, en general, resulta aplicable a cualquier entidad que forme parte del sector público, entre las cuales están las

9 STS de 17 de mayo de 2012, recurso 2616/2009.

10 En el momento de escribir estas páginas está vigente el Texto Refundido de la Ley de Contratos del Sector Público, aprobado por el Real Decreto Legislativo 3/2011 (en adelante, LCSP). No obstante, se encuentra en avanzado estado de tramitación, en las Cortes Generales, el Proyecto de Ley de Contratos del Sector Público que, con más de dos años de retraso, llevará a cabo la transposición de las nuevas directivas en la materia. Dicho proyecto coincide, sustancialmente, con la ley vigente y, en buena lógica, no debería diferir mucho del texto que definitivamente se apruebe como ley, ya que se trata de una regulación que procede de las directivas y de la jurisprudencia del Tribunal de Justicia de la UE. He optado, por ello, por indicar a pie de página los preceptos de la ley vigente y los correspondientes del Proyecto de Ley (en adelante, P-LCSP). 
sociedades mercantiles públicas ${ }^{11}$, cuando dichas entidades celebren contratos cuyo objeto esté comprendido en el ámbito de esta ley (los contratos típicos - de obras; concesión de obras públicas; concesión de servicios; suministro y servicios-y los contratos administrativos atípicos o especiales). Además, y en particular, resultará de aplicación en términos sustancialmente idénticos a los que rigen para las entidades del sector público que tienen la condición de administraciones públicas, cuando la sociedad mercantil tenga la consideración de "poder adjudicador», que es un concepto funcional y material que prescinde totalmente de la forma y naturaleza jurídica que adopte la entidad contratante, para penetrar en su sustrato material preguntándose por cosas tales como qué hace esa sociedad, quién la financia o quién la controla. La de "poder adjudicador», que es una noción del derecho de la UE, es una categoría que se define diciendo que, aparte de las administraciones públicas, las fundaciones públicas o las mutuas colaboradoras de la Seguridad Social, lo son: i) todas las demás entidades con personalidad jurídica propia distintas de las anteriores ii) que hayan sido creadas específicamente para satisfacer necesidades de interés general que no tengan carácter industrial o mercantil, iii) siempre que uno o varios sujetos que deban considerarse poder adjudicador, bien financien mayoritariamente su actividad, bien controlen su gestión o bien nombren a más de la mitad de los miembros de su órgano de administración, dirección o vigilancia ${ }^{12}$. Teniendo en cuenta que lo que no tiene que ser «industrial o mercantil» no es la entidad, sino «las necesidades de interés general» para cuya satisfacción ha sido específicamente creada, resulta que si, en una sociedad mercantil del sector público se dan esas circunstancias que, por lo demás, han sido interpretadas por el Tribunal de Justicia de la UE de una forma extraordinariamente amplia ${ }^{13}$, la mercantil contratará con sujeción al derecho administrativo. Con lo cual esa persona jurídica privada que, en teoría, actúa en régimen de derecho privado, estará sujeta a las disposiciones de esta ley en materia — entre otras ${ }^{14}$ — de actos de preparación y adjudicación del contrato,

11 Art. 3.1.d) LCSP y 3.1.h) P-LCSP.

12 Arts. 3.3.b) LCSP y 3.3.d) P-LCSP.

13 Sobre este concepto y su interpretación por el TJUE me remito a lo que he expuesto en C. Chinchilla Marín (2011), «La jurisprudencia del TJUE sobre contratos públicos (I): Ámbito subjetivo y objetivo de aplicación de las directivas», en M. Sánchez Morón (coord.) y J. del Olmo Alonso (dir.), El derecho de los contratos públicos en la Unión Europea y sus Estados miembros (págs. 39-76), Valladolid: Lex Nova; Alcalá de Henares: Universidad de Alcalá, y, más recientemente, desde otra perspectiva, véase Chinchilla Marín (2016).

14 Los arts. 20.1 LCSP y 26 P-LCSP definen como «contratos privados» los que celebren las entidades del sector público que siendo poder adjudicador no reúnan la condición de administraciones públicas. Coincidiendo en gran parte con el art. 20.2 LCSP, el art. 26.3 
modificación de los contratos, revisión de oficio ${ }^{15}$ y recurso especial ${ }^{16}$, dándose, de nuevo, la anomalía de considerar que una sociedad mercantil puede dictar actos administrativos, como así los califica literalmente el Proyecto de Ley de Contratos del Sector público cuando dice, en su art. 41.2, que:

A los exclusivos efectos de la presente Ley, tendrán la consideración de actos administrativos los actos preparatorios y los actos de adjudicación de los contratos de las entidades del sector público que no sean Administraciones públicas [...].

A continuación, el precepto establece que la revisión de oficio de estos actos se ejercerá de conformidad con la Ley de Procedimiento Administrativo Común, si bien, no por la propia sociedad mercantil, sino por el titular del departamento, órgano, ente u organismo al que esté adscrita la entidad privada o al que corresponda su tutela. Ciertamente, así se salva la contradicción que supone atribuir potestades administrativas a una sociedad (la de revisión de oficio, sin duda, lo es), pero, a cambio, se pone en evidencia la intensidad del dominio que el ente público matriz ejerce sobre su sociedad mercantil, ya que aquel, de oficio, puede anular los actos adoptados por esta ${ }^{17}$.

A la luz de todo lo dicho, cabe concluir, en mi opinión, que carece de sentido, y es una contradicción, calificar — como hace la Ley ${ }^{18}$ - de "contratos privados» a los contratos cuyo objeto esté comprendido en el ámbito de aplicación de la LCSP (obra, suministro, servicios, etc.), solo por el hecho de que la entidad contratante sea una sociedad mercantil pública (u otra entidad del sector público que no tenga la condición de Administración pública), cuando resulta que dichos contratos están regulados por el derecho administrativo de la contratación pública en tantos y tan sustanciales aspectos como son no solo

del anteproyecto establece que cuando se trate de contratos cuyo objeto esté comprendido en el ámbito de esta ley, «se regirán por lo dispuesto en el Título I del Libro Tercero de la misma, en cuanto a la preparación y a la adjudicación de aquéllos [y] en cuanto a sus efectos y extinción les serán aplicables las normas de derecho privado, salvo lo establecido en materia medioambiental, social o laboral, de condiciones especiales de ejecución, de modificación de contrato, de cesión y subcontratación, de racionalización técnica de la contratación; y la causa de resolución del contrato referida a la imposibilidad de ejecutar la prestación en los términos inicialmente pactados, cuando no sea posible modificar el contrato conforme a los art.s 202 y 203, a las que se refiere el art. 316».

15 Arts. 34 LCSP y 41 P-LCSP.

16 Arts. 40 LCSP y 44 P-LCSP.

17 La cuestión de la inexistencia de independencia real de la sociedad mercantil respecto del ente público titular de sus acciones se tratará en el apartado siguiente.

18 Me remito a lo dicho en la nota 14 . 
los referentes a su fase de preparación y adjudicación (los tradicionalmente denominados «actos separables»), sino, también, determinados aspectos de sus efectos y extinción, incluidas las modificaciones contractuales, y cuando, además, la revisión de su legalidad se efectúa en vía administrativa (revisión de oficio y recurso especial) y en vía contencioso-administrativa ${ }^{19}$.

\section{BIENES PÚBLICOS}

Probablemente la norma más destacable de cuantas contiene la LPAP sobre las sociedades mercantiles públicas es el art. 30.3, que establece nada más y nada menos que el privilegio de la inembargabilidad de los valores o títulos representativos del capital de determinadas sociedades mercantiles estatales. A pesar de su carácter de bienes patrimoniales o de dominio privado (arts. 4 y 7.2 LPAP), y a pesar de que la Constitución solo ha previsto el privilegio de la inembargabilidad para los bienes demaniales, el legislador lo ha extendido, sin embargo, a determinados bienes patrimoniales, entre los que se encuentran, como ya he dicho, los valores o títulos representativos del capital «de sociedades estatales que ejecuten políticas públicas o presten servicios de interés económico general $»^{20}$, conceptos ambos de tal amplitud que raramente habrá sociedades estatales que no se encuentren en alguno de los dos supuestos. Con esta norma, sorprendentemente de aplicación exclusiva a las sociedades mercantiles estatales, se establece para unos bienes calificados como «de dominio privado o patrimoniales» (art. 7.2 LPAP), el mismo régimen de prerrogativa que tienen los bienes demaniales o de dominio público de los entes públicos. Otro ejemplo más, pues, de que el derecho administrativo rige para las sociedades mercantiles.

Así mismo, cabe destacar que el Pleno no jurisdicional de la Sala Segunda del Tribunal Supremo, con fecha 25 de mayo de 2017, ha acordado que «los bienes, efectos, caudales o cualesquiera otros de cualquier índole que integren el patrimonio de las sociedades mercantiles participadas por el Estado u otras administraciones u organismos públicos, deben tener la consideración de patrimonio público y, por tanto, pueden ser objeto material del delito de malversación", siempre que concurran algunos requisitos como, por ejemplo, y entre otros, que la sociedad mercantil esté participada total o mayoritariamente por administraciones o entidades públicas, o esté controlada por estas, o haya recibido subvenciones en cuantía relevante, o preste, directa o indirectamente, servicios públicos.

19 Art. 27 P-LCSP.

20 El precepto se basa en la STC 166/1998, aunque haciendo, en mi opinión, una aplicación extensiva de la misma. 
Aparte de ello, las sociedades mercantiles estatales se definen por la LPAP como "patrimonio empresarial de la Administración General del Estado" y se regulan en un título - el VII- que contiene normas especiales para estas sociedades que suponen la excepción y la inaplicación de determinadas disposiciones del régimen común de las sociedades de capital.

Sin ánimo exhaustivo, entre otras cosas porque a una de las más importantes (la reestructuración del sector público empresarial) me referiré en el apartado siguiente, cabe destacar el art. 179 que prevé, en el mismo sentido que el art. 116 LRJSP, ya citado, que los administradores de las sociedades que actúen en cumplimiento de las instrucciones recibidas por su Ministerio de tutela quedarán exonerados de la responsabilidad prevista en el actual art. 236 del Real Decreto Legislativo por el que se aprueba el Texto Refundido de la Ley de Sociedades de Capital (LSC) ${ }^{21}$. Además, y esta ha sido una de las novedades introducidas por la LRJSP, y destacada en su exposición de motivos, la responsabilidad aplicable a los miembros de sus consejos de administración designados por la Administración General de Estado será asumida directamente por la Administración designante (art. 115).

Así mismo, cabe destacar el art. 180.2 LPAP, a tenor del cual los administradores de las sociedades de capital íntegramente del Estado no se verán afectados por la prohibición establecida en el apartado segundo del actual art. 213 LSC que impide ser administrador, entre otros, a los funcionarios al servicio de la Administración pública con funciones a su cargo que se relacionen con las actividades propias de las sociedades de que se trate ${ }^{22}$.

Para terminar con los ejemplos, me referiré, en último lugar, a que el derecho administrativo ha establecido una definición de "consejero independiente» propia y específica para las sociedades mercantiles estales, ya que dispone que tendrán dicha consideración «aquellos administradores que no presten servicios o que no se encuentren vinculados laboral o profesionalmente a la Dirección General del Patrimonio del Estado o al organismo público que fuera accionista de la sociedad; al órgano con funciones reguladoras sobre el objeto de la actividad de la sociedad; o al Ministerio que tenga atribuida la tutela de la sociedad $»^{23}$. Lo cual significa que bastará con que sean empleados de cualquier otro Ministerio, que no sea el de tutela, o, incluso, de cualquier

21 El art. 179 LPAP se remite al art. 133 de la Ley de Sociedades anónimas que entonces estaba vigente, es decir, el RDL 1564/1989.

22 Por las mismas razones expuestas en la nota anterior, el art. 180.2 LPAP hace referencia al art. 124 de la Ley de Sociedades anónimas vigente en aquel momento.

23 Art. 140.3 del Reglamento General de la Ley de Patrimonio de las Administraciones públicas, RD 1373/2009. 
Dirección General del Ministerio de Hacienda, que no sea la de Patrimonio (y siempre que el Ministerio de Hacienda no sea, a su vez, el de tutela) para que los consejeros tengan la consideración de independientes, cuando es sabido que los distintos Ministerios no son sino órganos de una única persona jurídica que es la Administración General del Estado.

\section{EMPLEO PÚBLICO}

La disposición adicional primera del Estatuto básico del Empleado público (RDL 5/2015) establece que "los principios contenidos en los arts. $52,53,54,55$ y 59 serán de aplicación en las entidades del sector público estatal, autonómico y local, que no estén incluidas en el art. 2 del presente Estatuto y que estén definidas así en su normativa específica». Esto significa que a las sociedades mercantiles, en cuanto que entidades del sector público distintas de las administraciones públicas y de los organismos públicos vinculados o dependientes de estas, que son los incluidos en el art. 2, les resulta de aplicación el mismo régimen jurídico que a los entes públicos en materias de tanta trascendencia como son los deberes de los empleados públicos, los principios éticos que deben regir su actuación, los principios rectores de su conducta y el acceso al empleo y adquisición de la relación de servicio que, de acuerdo con esta ley, debe regirse por los principios constitucionales de igualdad, mérito y capacidad, y realizarse mediante procedimientos que, además de los citados principios constitucionales, garanticen la publicidad de las convocatorias y de sus bases, la transparencia, imparcialidad y profesionalidad de los miembros de los órganos de selección, la adecuación entre el contenido de los procesos selectivos y las funciones o tareas a desarrollar y la agilidad, sin perjuicio de la objetividad, en los procesos de selección. Asimismo, rigen para ellas las normas relativas a la reserva de cupos para personas con discapacidad.

De nuevo se pone de manifiesto que, a pesar de la forma privada adoptada por este tipo de entidades, quedan sujetas al derecho público y, además, con la misma intensidad y alcance que si fuesen administraciones públicas. Ya que, aunque podría objetarse que la disposición adicional dice que les resultan de aplicación «los principios» contenidos en los preceptos que cita, y no los preceptos en sí, lo cierto es que esa precisión carece de trascendencia práctica por la sencilla razón de que, por un lado, todos esos preceptos lo que contienen o establecen son, precisamente, principios (arts. 52, 53, 54 y 55) y, de otro, porque respecto del único precepto de los enumerados en la disposición adicional primera que no establece principios, sino reglas, y muy concretas (la reserva de un cupo del $7 \%$ para discapacitados), no creo que pueda extraerse «un principio» que sea distinto de la regla en sí, ya que aplicar un porcentaje 
menor del $7 \%$ no sería un principio, sino la rebaja o minoración de una regla y eso no es lo que dice la disposición adicional primera.

Un buen ejemplo de que las entidades de derecho privado tienen un régimen de derecho público, también, en lo que se refiere a su personal, lo constituye el hecho de que la jurisprudencia haya llegado a aplicar al director general de una entidad jurídico-privada (la Fundación Teatro Lírico de Madrid) el régimen previsto para los altos cargos de la Administración pública e, incluso, a asumir que el personal de las entidades privadas del sector público es titular del derecho fundamental del art. 23.2 de la Constitución (acceso en condiciones de igualdad, y por mérito y capacidad, a las funciones y a los cargos públicos), todo ello sobre la base de «equiparar», como literalmente dice el Tribunal Constitucional, en su ATC 206/1999, la entidad privada a un ente público ${ }^{24}$ :

En efecto, el hecho de tratarse de una relación jurídico laboral especial sometida «a priori» no a la normativa funcionarial sino al Real Decreto 1382/1985 (y sólo en algunos aspectos al ET) no significa que no se le deban aplicar ciertas reglas y principios propios del personal al servicio de las Administraciones Públicas, pues en el presente caso la empresa, si bien formalmente persona jurídicoprivada, puede equipararse en realidad a un Ente público con capital y fines también públicos que actúa en el tráfico jurídico utilizando sólo de manera instrumental la veste fundacional. Por ello, el puesto de Director General de la Fundación del Teatro Lírico es uno más de los engranajes de la política cultural y de espectáculos de dos Administraciones (el Estado y la Comunidad Autónoma de Madrid) y, en esa medida, asimilable a los altos cargos o personal eventual de confianza política (previstos con carácter general en el art. 20.2 de la Ley 30/1984). [...]

Luego estamos en presencia, por un lado, de un ente privado fundacional que, para lo que aquí interesa, actúa materialmente como un organismo público bajo la dependencia directa de dos Administraciones, y por otro de una persona libremente elegida y nombrada por el Patronato de la Fundación del Teatro Lírico y que suscribió el contrato con la entonces Presidenta de dicha Fundación (la Ministra de Cultura). Y dicha persona, como señala el recién citado art. 1.2 del Real Decreto 1382/1985, ejercía sus competencias sometida a las directrices de política teatral y musical diseñada por el Patronato y cuyo

24 Sobre este auto y, en general, sobre la cuestión del significado de la personalidad jurídica de las fundaciones del sector público, véase J. García-Andrade Gómez (2013), «La reestructuración del sector público fundacional», Anuario de Derecho de Fundaciones, 4. Algunas ideas expuestas en el presente trabajo son fruto de la reflexión y el debate con el autor citado, en el seno de la Facultad de Derecho de la Universidad de Alcalá, de la que ambos somos profesores. 
puesto era por consiguiente asimilable, en cuanto al régimen de nombramiento y de cese, a los altos cargos de la Administración o incluso al personal de libre designación (respecto del cual hemos hablado en otras ocasiones de "cese acordado libremente, como libre fue el nombramiento» en el que «la misma libertad que hay para designar la hay para destituir»).

\section{RESPONSABILIDAD EXTRACONTRACTUAL}

Una de las novedades introducidas por la LRJSP en el régimen de responsabilidad patrimonial de las administraciones públicas ha sido la de extender dicho régimen jurídico que, como es sabido, se caracteriza por ser un régimen de responsabilidad objetiva, a toda la actuación administrativa, es decir, también a la realizada en régimen de derecho privado, incluso en los supuestos en los que la Administración actúe a través de una entidad de derecho privado (art. 35 LRJSP) ${ }^{25}$.

Pocas cosas resultan claras en este precepto que, sin duda, dará lugar a numerosas y variadas interpretaciones, pero si algo puede decirse del mismo es que, una vez más, prescinde del hecho de que sean privadas tanto la forma de personificación a través de la que actúe la Administración como la naturaleza de la relación jurídica que entable y, dentro de la cual, cause el daño, para determinar que, ello no obstante, el régimen jurídico de la responsabilidad extracontractual no será el del derecho privado (por «culpa o negligencia», ex art. 1902 del Código Civil) sino el del derecho administrativo (por «funcionamiento normal o anormal» de los servicios públicos» ex art. 32.1 LRJSP).

Como he dicho, y excluido que el precepto pueda estar refiriéndose a los supuestos en los que la Administración actúa a través de un concesionario o contratista, ya que dichos supuestos tienen su regulación específica en la Ley de Contratos del Sector público, a la que, por lo demás, expresamente se remite el art. 32.9 de la LRJSP²6, no es fácil desentrañar el significado del supuesto

25 Art. 35. Responsabilidad de derecho privado. «Cuando las Administraciones públicas actúen, directamente o a través de una entidad de Derecho privado, en sus relaciones de esta naturaleza, su responsabilidad se exigirá de conformidad con los arts. 32 y siguientes, incluso cuando concurra con sujetos de Derecho privado o la responsabilidad se exija directamente a la entidad de Derecho privado a través de la cual actúe la Administración o a la entidad que cubra su responsabilidad».

26 De acuerdo con lo establecido en el art. 214 LCSP (art. 194 P-LCSP), de los daños que cause el contratista a terceros, durante la ejecución del contrato, responde el contratista, salvo que dichos daños sean consecuencia inmediata y directa de una orden de la Administración o de los vicios del proyecto elaborado por ella misma. 
previsto en este precepto, es decir, qué hay que entender, exactamente, por actuación de la Administración en relaciones de derecho privado, que no sean, obviamente, de naturaleza contractual, puesto que esta disposición se refiere a la responsabilidad patrimonial o extracontractual de las administraciones públicas, y qué debe entenderse por actuación de las administraciones públicas $a$ través de una entidad de derecho privado. En mi opinión, no cabe descartar que este precepto, y el régimen de responsabilidad objetiva que establece, resulte de aplicación a cualquier actuación de una sociedad mercantil pública ya que, por un lado, y al menos teóricamente, las relaciones jurídicas entabladas por una sociedad mercantil del sector público deberían merecer la calificación de relaciones de derecho privado y, por otro, en cuanto que entidades instrumentales creadas por una Administración para cumplir con su función constitucional de servir al interés general (art. $103 \mathrm{CE}$ ), también, en principio, debería entenderse que la actuación de una sociedad mercantil siempre es la actuación de la Administración pública de la que es un mero instrumento. Y es que, más allá de que, formal y nominativamente, se puedan calificar unas actuaciones administrativas como de derecho público y otras como de derecho privado, en lo que no cabe hacer distinciones ni separaciones es en lo que, en todo caso, hace la Administración, porque solo es una cosa: «servir con objetividad a los intereses generales», como dice el art. 103 de la Constitución. Por eso, la Administración podrá crear entidades de derecho público o entidades de derecho privado, pero siempre será para lo mismo, para cumplir la única función que tiene: servir al interés general. De ahí que, en mi opinión, cuando una sociedad mercantil del sector público actúe, estará, en último término, actuando la Administración pública de la que depende para servir al interés general. No hay una actuación administrativa que sirve al interés general y otra que no lo hace. Solo hay una actuación administrativa "constitucionalmente posible», aunque haya distintas formas jurídicas de revestirse para realizarlas. De ahí que el Tribunal Supremo, invocando el «principio de especialidad de las empresas públicas», anulase en su día el Acuerdo del Pleno del Ayuntamiento de Barcelona por el que se constituyó una sociedad mercantil cuyo objeto era demasiado amplio, vago e indefinido, por entender que siempre que una Administración pública crea una sociedad tiene que definir para qué la crea exactamente, ya que solo así podrá determinarse si la actividad mercantil para la que se crea es o no de interés público y si, por consiguiente, dicha actividad conviene o no al interés público ${ }^{27}$.

27 STS de 10 de octubre de 1989, RJ $1989 \backslash 7352$. 


\section{LA PERSONALIDAD JURÍDICA DE LAS SOCIEDADES MERCANTILES PÚBLICAS: ¿̇REALIDAD O FICCIÓN?}

\section{LA BÚSQUEDA DE LA RESPUESTA EN LOS PRONUNCIAMIENTOS DEL TRIBUNAL CONSTITUCIONAL Y DEL TRIBUNAL SUPREMO}

Desde el derecho mercantil hace tiempo que se llamó la atención sobre el verdadero significado de la personalidad jurídica en derecho público. Concretamente, Alonso Ureba criticó el abuso que en derecho público se hacía de las categorías del derecho privado y, en particular, de las personificaciones jurídico-privadas y defendió que, como meros instrumentos organizativos de la Administración que son, estas personificaciones tienen un sentido puramente técnico y que, por tanto, la unidad estructural y funcional de la Administración no queda rota por la declaración formal de la personalidad ${ }^{28}$.

Aparte de las reflexiones que, en sentido parecido, se han hecho también desde la doctrina administrativista ${ }^{29}$, son los tribunales, incluido el Tribunal Constitucional, los que han sostenido que no existe, realmente, autonomía en las

28 A. Alonso Ureba (1985), La empresa pública. Aspectos jurídico-constitucionales y de derecho económico, Madrid: Montecorvo, págs. 283-294.

29 Así lo pone de manifiesto García-Andrade (2013) cuando, al estudiar las normas que regulan la reestructuración del sector público fundacional, concluye que dichas normas no reconocen a las fundaciones públicas la autonomía que es propia de las fundaciones privadas frente a las autoridades públicas e, incluso, frente a su fundador. Todo ello — sostiene el autor- porque ese conjunto de normas «concibe el sector público como una unidad con entidad propia que, al servicio del interés general, se eleva por encima de las personalidades jurídicas de las entidades que lo integran a las que sólo se atribuye una posición instrumental. Hasta el punto de que [...] se permite la reestructuración de entidades o la subrogación de unas por otras, sin que los terceros puedan entender que tales transformaciones suponen una alteración de las relaciones jurídicas en las que formen parte».

Yo misma he reflexionado sobre ello, a partir del principio de unidad del patrimonio del Estado, para poner en cuestión que los patrimonios de los organismos públicos instrumentales, que se califican como "propios», sean realmente patrimonios separados y autónomos del patrimonio de la Administración General. Existen preceptos en la Ley 33/2003 que, en mi opinión, vendrían a demostrar que el patrimonio del Estado, integrado por el patrimonio de la Administración General del Estado y el patrimonio de sus organismos públicos, es único y que no existe, por tanto, en último término, una separación real de personas jurídicas, C. Chinchilla Marín (2001), Los bienes patrimoniales del Estado, Madrid: Marcial Pons, págs. 158-169, y C. Chinchilla 
personificaciones instrumentales de las administraciones públicas respecto de estas, y que, en definitiva, todo, en el sector público, es reconducible a una unidad.

$\mathrm{Al}$ argumento de la falta de autonomía o independencia de una entidad instrumental respecto del poder público del que es mero instrumento acudió el Tribunal Constitucional, en su Sentencia 35/1983, para fundamentar su decisión de considerar que una sociedad mercantil pública —TVE SA- es un "poder público", a los efectos de entender que sus actos son susceptibles de ser recurridos en amparo si vulneran los derechos fundamentales protegidos con este recurso $^{30}$. El Tribunal rechazó que existiese la causa de inadmisibilidad invocada por el abogado del Estado, en el sentido de que TVE SA, por su naturaleza de entidad privada, no podía ser considerada como poder público y, en consecuencia, sus actos no podían ser objeto de recurso de amparo, argumentando lo siguiente:

Cuando el servicio [público] queda reservado en monopolio a un establecimiento cuya creación, organización y dirección son determinadas exclusivamente por el poder público no cabe duda de que es este el que actúa a través de persona interpuesta, pero en modo alguno independiente. La necesidad de hacer más flexible el funcionamiento de estos entes interpuestos puede aconsejar el que se dé a su estructura una forma propia del Derecho privado y que se sometan a éste los actos empresariales que debe llevar a cabo para el ejercicio de su función, pero ésta, en cuanto dirigida directamente al público como tal, ha de entenderse vinculada al respeto de los derechos y libertades reconocidos en el capítulo II del título I de la Constitución, según dispone el art. 53.1 de ésta, y, en consecuencia, los ciudadanos protegidos también frente a ella con los instrumentos que el ordenamiento les ofrece para salvaguardarla de sus derechos fundamentales frente a los actos del poder.

Unos años después, en su Sentencia 14/1986, el Tribunal Constitucional declaró que:

[...] la instrumentalidad de los entes que se personifican o que funcionan de acuerdo con el Derecho privado, remite su titularidad final a una instancia administrativa inequívocamente pública, como público es también el ámbito

Marín (2004), Comentarios a la Ley 33/2003, del Patrimonio de las Administraciones públicas, Madrid: Civitas, págs. 19-20.

30 De acuerdo con el art. 41.2 de la LOTC, «el recurso de amparo constitucional protege, en los términos que esta Ley establece, frente a las violaciones de los derechos y libertades a que se refiere el apartado anterior, originadas por las disposiciones, actos jurídicos, omisiones o simples vías de hecho de los poderes públicos del Estado, las Comunidades Autónomas y demás entes públicos de carácter territorial, corporativo o institucional, así como de sus funcionarios o agentes». 
interno de las relaciones que conexionan dichos entes con la Administración de la que dependen, tratándose en definitiva de la utilización por la Administración de técnicas ofrecidas por el Derecho Privado, como un medio práctico de ampliar su acción social y económica.

Más tarde, en su Sentencia 52/1994, el Tribunal Constitucional volvería a insistir en la misma idea diciendo:

Que la Administración actúe sometida al Derecho mercantil o civil no la exonera de su deber de respetar el orden constitucional de competencias. Resulta indiferente que su actuación sea llevada a cabo a través de órganos y servicios encuadrados en su organización matriz, o que por el contrario sea realizada por entidades con personalidad jurídica propia, pero controladas y dirigidas por la Administración del Estado. Tanto en un supuesto como en el otro, los actos emanados de la Administración estatal deben circunscribirse al ámbito que el bloque de la constitucionalidad mantiene como competencia del Estado, y deben respetar los ámbitos que cada Estatuto de Autonomía ha atribuido a la competencia de la respectiva Comunidad Autónoma.

Que la Administración posea las fincas rústicas situadas en Andalucía, que han dado origen al presente proceso constitucional, a través de personas jurídicas intermedias, es irrelevante. Igualmente irrelevante resulta que tales entes instrumentales se configuren como sociedades mercantiles, sometidas al Derecho privado.

Por su parte, el Tribunal Supremo, en su Sentencia de 22 de julio de $1986^{31}$, de la Sala de lo Contencioso-Administrativo, puso de manifiesto que:

[...] en último término, la personificación es sólo una alternativa organizadora que ni siquiera es suficientemente identificadora. No hay, en efecto, en el Ordenamiento español una regulación de la persona jurídica en virtud de la cual baste con invocar ese sintagma para que sepamos qué régimen jurídico hay que aplicar. Éste se articula para cada caso, de manera que más que de persona jurídica cabe hablar —en plural— de personas jurídicas, y el régimen jurídico de la personalidad es gradual [...].

Más recientemente, en la Sentencia de 17 de mayo de 2012, ya citada, el Tribunal Supremo ha afirmado que:

Hay una ruptura de los esquemas conceptuales tradicionalmente aceptados para distinguir lo público de lo privado, y hay también, finalmente, un abandono de los criterios clásicos determinantes de la teoría General del Derecho de la personalidad jurídica diferenciada. Han sido razones de eficacia administrativa

31 STS de 22 de julio de 1986, RJ 198615549. 
las que tradicionalmente se han invocado para justificar la creación de estas personificaciones diferenciadas que son los entes instrumentales. Estos, como ya se ha dicho, son puras técnicas organizativas dirigidas a conseguir en lo funcional y en lo financiero un marco de flexibilidad de actuación no ofrecido por el Derecho administrativo ordinario.

Además de estos pronunciamientos jurisprudenciales, que ya de por sí son importantes, existen regulaciones en el derecho vigente que, de facto, suponen la negación de la personalidad jurídica de las sociedades mercantiles públicas respecto de la Administración de la que dependen, y que tratan a estas «personas jurídicas» como si no existieran, esto es, como si no fueran un sujeto distinto y diferenciado de la Administración pública de la que dependen. Veamos algunos ejemplos de ello.

\section{LA BÚSQUEDA DE LA RESPUESTA EN LA LEGISLACIÓN ADMINISTRATIVA}

A) La gestión directa de servicios públicos a través de entidades instrumentales y la categoría juridica de los "medios propios» en la legislación de contratos públicos

Tradicionalmente, las distintas leyes que han regulado las formas de gestión de los servicios públicos han partido de la diferenciación entre "gestión directa» $y$ "gestión indirecta» de los mismos ${ }^{32}$. La gestión indirecta es la que se realiza a través de un contrato, mientras que la "directa» es aquella en la que la Administración presta el servicio mediante una entidad de derecho público o mediante una sociedad cuyo capital sea, en su totalidad, de titularidad pública. Las sucesivas leyes de contratos públicos aclaraban que, en los casos de gestión directa, no resultaba de aplicación la Ley de Contratos por la sencilla razón de que, en estos supuestos, no hay contrato. De ahí que la expresión utilizada por la Ley fuese que, en estos casos, la Administración prestadora del servicio lo que hace es «atribuir» la gestión del servicio a la sociedad mercan$\mathrm{til}^{33}$. No se contrata con ella para que preste, en nombre de la Administración, el servicio a los usuarios, sino que se le atribuye dicha prestación; esto es, se le encarga o, más aún, se le impone la obligación de prestar el servicio. Por el contrario, en los casos de gestión indirecta, se contrata la gestión del servicio público con un tercero, en las diversas modalidades de concesión, gestión interesada, concierto o sociedad de economía mixta (art. 277 LCSP).

32 Arts. 8.2, 275.1 y 277 LCSP y art. 85 de la Ley de Bases de Régimen Local (Ley 7/1985).

33 Art. 8.2 LCSP. 
El Proyecto de Ley de Contratos, aunque no contenga preceptos equivalentes a los que aquí acaban de citarse, mantiene, en lo sustancial, y a los efectos de lo que aquí se está analizando, la misma regulación. Ya que, si bien es cierto que, como consecuencia de la supresión del contrato de gestión de servicios públicos, y su sustitución por el contrato de concesión de servicios y el contrato de servicios, la Ley ha dejado de hablar, explícitamente, de formas de gestión de los servicios públicos, no lo es menos que los servicios públicos pueden seguir prestándose bien de forma directa, bien de forma indirecta, bajo la modalidad, en este último caso, del contrato de concesión de servicio o del contrato de servicios ${ }^{34}$. Es más, lo que ahora se regula bajo la denominación de «encargos a medios propios personificados» no es más que la posibilidad de que un poder adjudicador ejecute, de forma directa, a través de un ente instrumental suyo, las prestaciones propias de los distintos contratos regulados en esta ley (obras, suministros, servicios, concesión de obras y concesión de servicios).

Bajo la expresiva rúbrica «encargos de los poderes adjudicadores a medios propios personificados», el art. 32 del Proyecto de Ley de Contratos del Sector público establece que la Administración y demás entidades del sector público con la consideración legal de poderes adjudicadores:

[...] podrán ejecutar de manera directa las prestaciones propias de los contratos de obras, suministros, servicios, concesión de obras y concesión de servicios, a cambio de una compensación tarifaria, valiéndose de otra persona jurídica distinta a ellos, ya sea de derecho público o de derecho privado, previo encargo a esta, con sujeción a lo dispuesto en este artículo, siempre y cuando la persona jurídica que utilicen merezca la calificación jurídica de medio propio personificado respecto de ellos.

Una persona jurídica merece la consideración de medio propio cuando cumpla todos y cada uno de los requisitos establecidos en el art. 32.2, entre los que se encuentra el de que, cuando la persona jurídica sea una sociedad mercantil, su capital sea íntegramente público ${ }^{35}$.

34 En un trabajo de estas características no procede entrar en el análisis de algo tan complejo, y tan alejado del tema que es objeto de estudio, como es la nueva caracterización del contrato de concesión de servicios y su distinción del contrato de servicios.

Los requisitos son: a) que el poder adjudicador que realiza el encargo ejerza sobre el ente destinatario del mismo un "control, directo o indirecto, análogo al que ostentaría sobre sus propios servicios o unidades», situación que se dará, en todo caso, cuando el poder adjudicador pueda conferirle encargos que sean de ejecución obligatoria, y siguiendo las instrucciones fijadas unilateralmente, para el ente destinatario, por así 
La consecuencia jurídica de encargar las prestaciones propias de los contratos de obras, suministros, servicios, concesiones de obras o de servicios es, sencillamente, que «el encargo no tendrá la consideración de contrato» ${ }^{36}$, por lo que, en consecuencia, no quedará sujeto a las estrictas normas de la contratación pública. Así, pues, no hay contrato, aunque la prestación se realice a través de una entidad con personalidad y patrimonio propios y diferenciados de la Administración pública que realiza el encargo; y, antes bien, se considera que dicha Administración está ejecutando "de manera directa» el objeto del contrato, aunque se reconozca, incurriendo en una contradicción, al menos gramatical, que la prestación se realiza «valiéndose de otra persona jurídica distinta». Por la misma razón, a las personas jurídicas que tienen la consideración legal de medios propios se les prohíbe participar en licitaciones públicas convocadas por el poder adjudicador del que sean medios propios personificados (art. 32. 2. d. $\left.2^{\circ}\right)^{37}$. Se parte, pues, de la falta de alteridad y, en consecuencia, de entender que, en el sector público, existe una unidad estructural y funcional entre las Administraciones públicas y sus entes instrumentales que no queda rota por el elemento formal de la personalidad jurídica ${ }^{38}$.

\section{B) La reestructuración del sector público empresarial}

Bajo la rúbrica «Reestructuración del sector público empresarial», los arts. 168 y siguientes de la LPAP establecen una regulación sobre la transmisión de acciones dentro del sector público estatal (entre la Administración general del Estado, sus entidades públicas y sus sociedades de capital íntegramente

establecerlo los estatutos o el acto de creación, de manera que exista una unidad de decisión entre ellos; b) que más del $80 \%$ de las actividades del destinatario del encargo se lleven a cabo en el ejercicio de los cometidos que le han sido confiados por el poder adjudicador; c) que, cuando el ente destinatario del encargo sea un ente de personificación jurídico-privada, la totalidad de su capital o patrimonio sea de titularidad o aportación pública; d) que la condición de medio propio personificado se reconozca expresamente en sus estatutos o su acto de creación.

36 Art. 32.1 P-LCSP.

37 Véase I. Gallego Corcoles (2015), «Nuevos desarrollos de la contratación in house en el Derecho español: los encargos a medios propios y servicios técnicos», en J. M. Gimeno Feliú (dir.), Observatorio de Contratos Públicos, Cizur Menor: Aranzadi. La autora llega a sostener, y lo comparto, que «en Derecho español se ha asumido que el dato de la personalidad es una ficción: no es que las adjudicaciones in house sean contratos excluidos de las Directivas, es que ni si quiera tienen la condición de contratos» (págs. 215-216).

38 Véase Alonso Uveda (1985: 284). 
estatal) que, una vez más, pone de manifiesto que la personalidad jurídica propia y diferenciada de estas sociedades se diluye y desaparece hasta el punto de considerar que, realmente, no hay un negocio jurídico de transmisión de la propiedad de las acciones entre personas jurídicas diferentes, porque, en el fondo, todo el denominado "patrimonio empresarial» es reconducible a la Administración General del Estado, única titular y propietaria de estas acciones.

Lo primero que debe destacarse es que el cambio de titularidad en que consiste lo que se califica como una "reordenación interna» en el sector público estatal se produce, de forma unilateral e imperativa, por acuerdo del Consejo de Ministros. En segundo lugar, la Ley establece que estas operaciones no estarán sujetas a la legislación del mercado de valores y, lo que es más importante todavía, "no darán lugar al ejercicio de derechos de tanteo, retracto o cualquier otro derecho de adquisición preferente que estatutaria o contractualmente pudieran ostentar sobre dichas participaciones otros accionistas de las sociedades cuyas participaciones sean transferidas o, en su caso, de terceros a esas sociedades». Asimismo se establece que «la mera transferencia y reordenación de participaciones societarias que se realice en aplicación de esta norma no podrá ser entendida como causa de modificación o de resolución de las relaciones jurídicas que mantengan tales sociedades». A lo que hay que añadir que las acciones recibidas se registrarán en la contabilidad del nuevo titular por el mismo valor neto contable que tenían en el anterior titular y, por último, que todas estas operaciones estarán exentas de cualquier tributo estatal o local, incluidos los cedidos a las comunidades autónomas y los recargos autonómicos sobre tributos estatales.

Es el propio legislador el que acude a la idea de la personalidad jurídica única al decir que estos cambios de titularidad «no implican la entrada de un tercero ajeno al ámbito societario, sino que, por el contrario, solamente supone un cambio del órgano competente con mantenimiento de la titularidad estatal ${ }^{39}$. De hecho, se ha llegado a afirmar que lo que establece el art. 168

39 A este respecto, resulta muy ilustrativa la exposición de motivos de la Ley 7/2001, de 14 de mayo, de modificación de la Ley del Patrimonio del Estado, texto articulado aprobado por Decreto 1022/1964, de 15 de abril, en la que se introdujo la regulación que actualmente se encuentra contenida en la LPAP. Dice así:

«Esta configuración del procedimiento y competencias para ejecutar las actuaciones de reordenación viene complementada con una serie de normas de derecho sustantivo y fiscal cuya finalidad es garantizar la neutralidad de los cambios de titularidad de las participaciones siempre que ésta tenga lugar entre personas jurídico-públicas del Estado. El fundamento de estas modulaciones que se imponen sobre relaciones jurídicas y estatutos sociales existentes al entrar en vigor este precepto, entre ellas las relativas a 
LPAP «no es otra cosa que un cambio de «competencias administrativas» en la gestión de sociedades públicas» ${ }^{40}$. Y, en la misma línea, la Abogacía del Estado, con motivo de una consulta sobre el carácter gratuito u oneroso de la transmisión de unos terrenos por parte de una sociedad estatal a una entidad pública, también estatal, en ejecución de un acuerdo del Consejo de Ministros sobre reestructuración del sector público empresarial, concluyó que la transmisión era gratuita con base en los siguientes argumentos: i) que el acuerdo del Consejo de Ministros, en cumplimiento del cual se transmitían los terrenos en cuestión, se incardinaba en una operación de reestructuración del sector público empresarial del Estado, consistente en la extinción de una sociedad estatal mediante la cesión global de sus activos a otra sociedad estatal, la cual, seguidamente, tenía que transmitir a una entidad pública empresarial la propiedad de los terrenos en cuestión $^{41}$; ii) que aun cuando esta multiplicidad de empresas públicas tengan

los derechos de adquisición preferente o al mantenimiento de los negocios jurídicos, es claro.

En concreto, como verdaderos actos de reordenación de participaciones societarias dentro del sector público estatal, los cambios de titularidad que se produzcan por razón de este precepto entre entidades públicas no son otra cosa que un efecto reflejo del cambio del órgano o entidad con competencia administrativa para ejercer las facultades inherentes a la titularidad de tales participaciones. En este sentido, un cambio de adscripción ejecutado en virtud de la presente norma no supone alteración de los niveles de solvencia o seguridad de las relaciones jurídicas en las sociedades participadas, ni implica la entrada de un tercero ajeno al ámbito societario, sino que, por el contrario, solamente supone un cambio del órgano competente con mantenimiento de la titularidad estatal».

40 P. Olivera Massó (2008), «Comentario al art. 168 de la Ley 33/2003, de Patrimonio de las Administraciones públicas», en J. de Fuentes Bardají (dir.) e I. Gayarre Conde (coord.), Comentarios a la Ley del Patrimonio de las Administraciones públicas, Cizur Menor: Aranzadi. El autor explica que, a diferencia de la modificación de las competencias de los órganos administrativos, que se lleva a cabo a través de una norma, la modificación de las competencias que un organismo o entidad tiene sobre una sociedad mercantil se opera a través del cambio de propietario de las acciones de la misma. El autor califica, por ello, esta regulación como una potestad administrativa atribuida al Consejo de Ministros para cambiar la titularidad de las participaciones entre las empresas del sector público estatal.

41 El Consejo de Ministros adoptó el Acuerdo de 30 de abril de 2010, de racionalización del sector público empresarial, en virtud del cual la sociedad Ingruinsa, S. A. se extinguía mediante la cesión global de sus activos (entre los que estaban los terrenos adquiridos para la ejecución del parque empresarial «El Rebollar») a su único accionista, la sociedad Infoinvest; la cual quedaba obligada a transmitir «seguidamente» a la entidad pública empresarial SEPES la propiedad de los terrenos adquiridos para la 
personalidad jurídica y patrimonio propios, se trata, en rigor, de entidades instrumentales cuya propiedad última apunta al propio Estado, que es quien, directa o indirectamente, tiene la titularidad del capital social de estas empresas, lo que significa que el carácter oneroso de esas operaciones no se compadece bien con la condición de propietario o titular único de ese patrimonio empresarial que es quien a través de su máximo órgano, el Consejo de Ministros, ordena esa operación de reestructuración de tal patrimonio; y, por último, iii) que el principio de presunción de onerosidad de los negocios jurídicos, que tiene su campo natural de aplicación en el tráfico mercantil, no puede aplicarse en un ámbito muy distinto, cual es el conjunto de operaciones que se efectúan para reorganizar o reestructurar un sector empresarial que pertenece a un único propietario o titular y en el que no concurren las notas propias del tráfico mercantil, esto es, no son operaciones libremente acordadas por las sociedades afectadas por dicho acuerdo, sino, muy distintamente, operaciones impuestas a las mismas en virtud del poder de dirección que, como dominus, ostenta el Estado y que el mismo ejerce a través de su máximo órgano en su esfera o poder ejecutivo ${ }^{42}$.

\section{C) El régimen de impugnación de actos entre entes del sector público}

La Ley reguladora de la Jurisdicción Contencioso-administrativa (Ley 28/1999) niega la legitimación activa a las entidades de derecho público dependientes o vinculadas al Estado, a las comunidades autónomas o a las entidades locales, para recurrir la actividad de la Administración pública de la que dependan. Por tanto, aunque sean personas jurídicas distintas a «su» Administración, los organismos públicos no pueden interponer recurso contenciosoadministrativo contra la actividad de la misma ${ }^{43}$.

De manera más amplia, aunque solo aplicable al ámbito del Estado, se ha establecido un régimen de solución de controversias jurídicas entre los entes públicos y privados del sector público estatal verdaderamente excepcional, pues no solo prohíbe los recursos — administrativos y contencioso-administrativosentre estos entes, sino que, además, establece un procedimiento interno de solución de controversias en el que la última palabra, sin posibilidad de recurso, la tiene el Estado a través de una comisión integrada por varios ministros.

ejecución del parque empresarial en cuestión, conforme al Convenio de colaboración que habían firmado, en 2006, la SEPI y el Ayuntamiento de Requena.

42 Dictamen de la Abogacía del Estado de 25 de marzo de 2015, JUR\2015\129070.

43 Art. 20. c) LJCA. El precepto exceptúa de la prohibición a las Administraciones independientes, esto es, a los entes a los que «la Ley haya dotado de un estatuto específico de autonomía respecto de dicha Administración». 
En efecto, la Ley 11/2011, de 20 de mayo, de reforma de la Ley 60/2003, de Arbitraje y de regulación del arbitraje institucional en la Administración General del Estado, establece que las controversias jurídicas relevantes ${ }^{44}$ que se susciten entre la Administración General del Estado y cualquiera de sus organismos públicos se resolverán por el procedimiento previsto en este precepto, sin que pueda acudirse a la vía administrativa ni jurisdiccional para resolver estas controversias. Este procedimiento — continúa diciendo la Ley— será, asimismo, aplicable a las controversias jurídicas que se susciten entre las sociedades mercantiles estatales y las fundaciones del sector público estatal con su Ministerio de tutela, la Dirección General de Patrimonio o los organismos o entidades públicas que ostenten la totalidad del capital social o dotación de aquellas, salvo que se establezcan mecanismos internos de resolución de controversias.

El procedimiento consiste en que, planteada una controversia, las partes enfrentadas la pondrán, de forma inmediata, en conocimiento de la Comisión Delegada del Gobierno para la Resolución de Controversias Administrativas, la cual estará presidida por el ministro de la Presidencia y tendrá como vocales natos al ministro de Economía y Hacienda y al ministro de Justicia, correspondiendo también a este último designar, dentro de su ámbito, al órgano que ejerza la secretaría de la Comisión. Además, se integrarán en la Comisión el ministro o ministros de los departamentos afectados por la controversia.

Como ya he adelantado, la Comisión dictará resolución estableciendo de forma vinculante para las partes las medidas que cada una de ellas deberá adoptar para solucionar el conflicto o controversia planteados, no siendo dicha resolución recurrible ante los tribunales de justicia por las partes en conflicto.

En resumen, pues, las personas jurídicas del sector público estatal, a pesar de ser eso, personas jurídicas distintas de la Administración General del Estado, no pueden recurrir ni contra esta ni contra el resto de entidades del sector público estatal, lo que, en el fondo, denota, una vez más, que la personalidad jurídica para el derecho público no tiene el mismo significado que para el derecho privado ya que, en general, se diluye en la personalidad jurídica única del ente del que son meros instrumentos o formas de organización interna ${ }^{45}$.

44 Según el apdo. 2 de la DA única de la Ley 11/2011, «a los efectos de esta disposición, se entenderán por controversias jurídicas relevantes aquellas que, con independencia de su cuantía, generen o puedan generar un elevado número de reclamaciones, que tengan una cuantía económica de al menos 300000 euros o que, a juicio de una de las partes, sea de esencial relevancia para el interés público».

45 El apdo. 60 de la DA única de la Ley 11/2011 establece que este procedimiento de resolución de controversias no se aplicará: a) a cuestiones de naturaleza penal, pero sí a las relativas al ejercicio de las acciones civiles derivadas de delitos o faltas; b) a cues- 
El Tribunal Supremo ha demostrado, recientemente, tener también esa concepción de lo que deba entenderse por personalidad jurídica en el derecho administrativo, al prescindir de la personalidad jurídica, propia y diferenciada, de un organismo autónomo respecto de su comunidad autónoma, para concluir que, a efectos de entender interrumpido el plazo de prescripción de una acción, es indiferente que quien reclame la deuda sea el ente acreedor de la misma, o la comunidad autónoma de la que dicho ente depende. Todo ello sobre la base de acudir a una categoría — la de «la cesta única de los créditos» de la Hacienda autonómica — que podríamos traducir por la idea de que «Hacienda son todos», es decir, todos los entes de un sector público y que, por lo tanto, la personalidad jurídica diferenciada es, a estos efectos, un dato irrelevante ${ }^{46}$.

En efecto, en virtud de sucesivos convenios firmados por una universidad, la Comunidad de Madrid y el IVIMA, este último construyó y entregó a la universidad viviendas para estudiantes y, en su día, reclamó la cantidad correspondiente a su coste. A pesar de que había sido el IVIMA el que había requerido a la universidad el pago de lo debido, fue la comunidad autónoma la que interpuso un recurso contencioso-administrativo contra lo que denominó «desestimación presunta del requerimiento de pago». El Tribunal Superior de Justicia entendió que la acción había prescrito, pues la Comunidad de Madrid no había reclamado la deuda y, al no ser el IVIMA quien interponía el recurso contencioso-administrativo, no podía considerarse que sus sucesivos requerimientos de pago hubieran interrumpido el plazo de prescripción. La universidad argumentó, entre otras cosas, que al ser únicamente el IVIMA el que le había requerido el pago, y tratarse de un organismo autónomo con personalidad jurídica diferenciada de la comunidad autónoma, no se había interrumpido la prescripción por no darse la necesaria identidad subjetiva y objetiva.

El Tribunal Supremo no lo entendió así, pues, como ya he adelantado, estimó que los requerimientos del IVIMA sí habían interrumpido la prescripción de la reclamación que luego ejercería la Comunidad de Madrid en

tiones de responsabilidad contable que sean competencia del Tribunal de Cuentas, sujetas a la legislación específica reguladora de éste; c) a conflictos de atribuciones entre distintos órganos de una misma Administración pública, que se regularán por sus disposiciones específicas; d) a las cuestiones derivadas de las actuaciones de control efectuadas por la Intervención General de la Administración del Estado, reguladas con carácter específico en la Ley 47/2003, General Presupuestaria, en la Ley 38/2003, General de Subvenciones, y demás normas de desarrollo de las mismas.

46 STS de 27 de noviembre de 2012, recurso 318/2012. Sobre esta cuestión también versa la STS de 2 de enero de 2013, recurso 1687/2012. 
la vía judicial. Sus argumentos, que reproduzco a continuación, conducen, en último término, a sostener que la personalidad jurídica de los entes instrumentales de las administraciones públicas no se diferencia de la personalidad jurídica de la Administración, dada la relación de dependencia que existe entre aquellos y esta.

Lo que el Tribunal Supremo argumenta en esta sentencia, dicho sea en términos muy resumidos, es lo siguiente:

El crédito del organismo autónomo IVIMA se integra en la cesta de créditos de la Hacienda de la Comunidad de Madrid, en virtud del Convenio celebrado entre esta y la Universidad.

El IVIMA, que es quien realizó los requerimientos de pago, es una persona jurídica con «cierta autonomía formal», pero «que no se desvincula del ente matriz creador», ni tiene frente a él «una independencia absoluta».

La vinculación e «interconexión máxima» que existe entre la Comunidad de Madrid y el IVIMA «ha de conducir inexorablemente a admitir la actividad del ente matriz en defensa y protección de los recursos que integran los medios económicos del organismo, puesto que los mismos son fondos públicos destinados al cumplimiento de las finalidades públicas que tiene encomendadas».

En conclusión — dirá el Tribunal Supremo- «no podemos estimar que no pueda la Comunidad de Madrid litigar en defensa de derechos que forman parte de sus organismos personificados puesto que esa autonomía funcional se centra en el cumplimiento de sus objetivos para el que asignan recursos, pero en ningún caso lo independizan del ente matriz, que sigue ostentando potestades de control y tutela sobre el mismo puesto que son fondos públicos los que se ventilan».

Así, pues, según el Tribunal Supremo, tratándose de fondos públicos, «la cesta» de los créditos es única y, por eso, la Comunidad de Madrid puede reclamar el pago de los mismos, aunque lo haga fuera de plazo, pues, a pesar de que dicha ley diga que prescribirá a los cuatro años el derecho de las instituciones y de la Administración de la Comunidad y de sus organismos autónomos al cobro de sus créditos (art. 36.1 de la Ley 9/990), el Supremo entiende que ese derecho, que corresponde a cada uno de los entes personificados, puede reclamarlo el acreedor, con efectos interruptivos de la prescripción, pero también el que no es acreedor, aunque antes no lo haya reclamado, porque Hacienda son todos los entes del sector público que, a estos efectos, no se diferencian como personas distintas.

Si ello es así, en aplicación del principio ubi commoda, ibi incommoda, debería concluirse que si, a efectos de cobrar créditos por parte de los entes del sector público la cesta es solo una, a efectos de pagar deudas también debería serlo y, sin embargo, eso ya no es tan evidente, como expondré en el siguiente epígrafe. 


\section{REFLEXIÓN FINAL, A LA LUZ DE TODO LO EXPUESTO, ACERCA DE UNA CUESTIÓN PRÁCTICA: ¿̇DEBE O NO RESPONDER LA ADMINISTRACIÓN MATRIZ POR LAS DEUDAS DE SUS SOCIEDADES MERCANTILES?}

A falta de una norma que, con carácter general, establezca explícitamente que las administraciones públicas responderán de las deudas contraídas por sus sociedades mercantiles, habrá que concluir que para las sociedades del sector público rige el principio de separación de la responsabilidad de la sociedad y de sus socios, consagrado en el art. 1 de la Ley de Sociedades de Capital.

Sin embargo, por todo cuanto aquí se ha expuesto, existen razones para poner en cuestión que, en el sector público, deba aplicarse, en los mismos términos que se aplica en el sector privado, la regla según la cual los socios que, en este caso serían la Administración pública o sus organismos públicos, no responden de las deudas de la sociedad.

En efecto, cabría preguntarse por qué se ha de aplicar esta regla, propia del derecho privado, en el sector público cuando, a lo largo de este trabajo, se ha puesto de manifiesto que las sociedades mercantiles públicas no son, realmente, personas jurídico-privadas, sino "un híbrido" de personificación jurídica al que antes que el derecho privado y preferentemente al derecho privado, se le aplica el derecho administrativo. O por qué debería aplicárseles el principio consagrado en el art. 1 de la Ley de Sociedades de Capital, cuando, a pesar de revestir la forma jurídico-privada de sociedad, el derecho público las llama "poderes públicos» e, incluso, reconoce que pueden ejercer potestades públicas y dictar actos administrativos.

Pero, sobre todo, por qué aplicarles el principio de incomunicabilidad de la responsabilidad, que no es más que la consecuencia de la existencia de una personalidad jurídica y un patrimonio propios y diferenciados, cuando el derecho público y los tribunales que lo aplican equiparan a las sociedades mercantiles con su socio (la Administración titular de sus acciones), negando que exista una personalidad jurídica realmente diferenciada y argumentando, como ha quedado expuesto en páginas anteriores, que la personificación, en derecho público, es solamente «una alternativa organizadora»; "un medio práctico de ampliar su acción social y económica», o "una pura técnica organizativa dirigida a conseguir [...] un marco de flexibilidad de actuación no ofrecido por el Derecho administrativo [...]». 


\section{RESUMEN DE LOS PRONUNCIAMIENTOS DE LA JURISPRUDENCIA CIVIL Y CONTENCIOSO-ADMINISTRATIVA SOBRE LA CUESTIÓN}

Si tuviésemos que responder con un sí o un no a la pregunta de cuál es el criterio que aplican los tribunales cuando tienen que resolver la cuestión de si la Administración matriz de una sociedad mercantil $-\mathrm{o}$, en general, de un ente institucional- es responsable o no de las deudas de sus entes instrumentales, no podríamos hacerlo. Y ello, por la sencilla razón de que, en esta, como en tantas otras cuestiones capitales, no hay un criterio jurisprudencial unánime, ni tan siquiera inequívocamente mayoritario. En efecto, frente al criterio de la equiparación o confusión de la Administración con sus entes instrumentales que, como hemos visto, los tribunales han aplicado en numerosas ocasiones al revolver cuestiones de la más de diversa índole, cuando se trata de dar respuesta a la cuestión — más concreta y, también, más onerosa para la Hacienda pública - de si la Administración responde o no por las deudas de las personas jurídicas que de ella dependen, entonces las respuestas de los tribunales fluctúan entre, básicamente, dos posiciones, a saber: la que considera que la existencia de la personalidad jurídica, también en derecho administrativo, impide imputar a la Administración matriz la responsabilidad contraída por sus entes o entidades instrumentales; y la posición que, por el contrario, entiende que no hay una distinción real entre la Administración y su ente instrumental y que, por consiguiente, responde la Administración; posición esta segunda que, a veces, se apoya en la teoría del levantamiento del velo y otras no $^{47}$.

Entre las sentencias que aplican el principio de separación de responsabilidades, cabe destacar la del Tribunal Supremo (Sala de lo Civil), de 31 de diciembre de 1993, en la que, ante una reclamación por un accidente de trabajo en una residencia de mayores, el Tribunal Supremo concluye que no debía responder el Ministerio de Trabajo (en contra de lo que habían mantenido el Juzgado de primera instancia y la Audiencia), sino el organismo autónomo del que dependía la residencia:

[...] la teoría de la unidad institucional del Estado no puede desconocer la legislación sobre Organismos Autónomos y la personalidad propia e

47 Sobre la aplicación del levantamiento del velo en el derecho administrativo, véase S. Ortiz Vaamonde (2004), El levantamiento del velo en el Derecho Administrativo. Régimen de contratación de los entes instrumentales de la Administración, entre si y con terceros, Madrid: La Ley; M. A. Recuerda Girela (2012), «La aplicación de la doctrina del levantamiento del velo como técnica para el cobro de las deudas de los entes del sector público", en M. A. Recuerda Girela (dir.), La morosidad del sector público en el cumplimiento de sus obligaciones (págs. 679-717), Madrid: Civitas. 
independiente del Inserso, así como su patrimonio separado, que impiden el desplazamiento de la responsabilidad extracontractual; la doctrina del levantamiento del velo, que parte de la existencia de mala fe, actuar fraudulento o abusivo en la personalidad jurídica para evitar responsabilidades, tampoco puede trasladarse al Estado y sus organismos autónomos, pues en modo alguno pueden achacárseles tales conductas en la organización de sus instituciones ${ }^{48}$.

Más recientemente —-2013 y 2015_, el Tribunal Supremo (Sala de lo Contencioso-Administrativo), en un supuesto en el que se trataba de determinar si el Ministerio de Hacienda respondía por determinadas actuaciones del Consorcio de la Zona Franca de Vigo, ha llegado a la misma conclusión que la Sala de lo Civil, pero por un "camino» argumental muy distinto al seguido por esta en la Sentencia de la Sala de lo Civil a la que antes me he referido. En estos dos casos, la Sala de lo Contencioso-Administrativo concluye que el Ministerio no responde porque no se ha acreditado que tutele la actuación del Consorcio y porque no existe un recurso de alzada impropio contra los actos del Consorcio ante el Ministerio ${ }^{49}$. Lo que parece indicar que, de haberse acreditado la existencia de tutela por parte del Ministerio sobre el Consorcio, puesta de manifiesto, singularmente, pero no exclusivamente, por la existencia de un recurso de alzada impropia, la conclusión hubiera sido la contraria.

También la Audiencia Nacional ha sostenido el principio de separación de personalidad jurídica y, por consiguiente, de responsabilidades, en un caso en el que se trataba de dilucidar si la Tesorería General de la Seguridad Social podía presentar una reclamación de daños y perjuicios frente a la Administración General del Estado (Ministerio de Justicia), basada en el funcionamiento anormal de los tribunales de justicia ${ }^{50}$. La Abogacía del Estado, haciendo uso de la teoría de la confusión de personalidades, argumentó que la Tesorería de la Seguridad Social no podía ser considerada «otra» Administración, sino que era un organismo público dotado de personalidad jurídica con el principal cometido de administrar el patrimonio de la Seguridad Social, pero que estaba sometido a la Administración General del Estado, por lo que «es» la propia Administración del Estado. La Audiencia Nacional rechaza este planteamiento y viene a decir, muy resumidamente expuesto, que los actos de los organismos públicos

48 STS de 31 de diciembre de 1993, recurso 1890/1991.

49 SSTS de 5 de noviembre de 2013, recurso 156/2012 y de 20 de noviembre de 2015, recurso 1040/2014.

50 SAN de 4 de junio de 2008, recurso 36/2005. En el caso de autos, la Tesorería General de la Seguridad Social ejerció la acción de responsabilidad patrimonial, por funcionamiento anormal de la justicia, como consecuencia del daño que había sufrido por un error cometido por un Tribunal Superior de Justicia. 
vinculados a una Administración pública son imputables a ellos mismos y no a la Administración matriz; que esa diferente imputación jurídica opera no solo frente a terceros, sino también entre los entes públicos entre sí; que cuando el legislador ha querido que la Administración matriz responda por los actos de sus entes instrumentales o vinculados, lo ha dispuesto expresamente (Ley 13/2000, MINTRA $)^{51}$; $y$, en definitiva, que la responsabilidad no se transmite, debiendo responder el ente público con cargo a su propio patrimonio.

Frente a este tipo de pronunciamientos judiciales, y otros que sostienen el mismo criterio $^{52}$, existen también numerosas sentencias que, partiendo de la identidad sustancial — por encima de la diferenciación formal— entre la Administración matriz y la persona jurídica vinculada a ella, aplican el criterio de la comunicabilidad de la responsabilidad entre una y otra, si bien argumentándolo de manera distinta e invocando, unas veces sí y otras no, la doctrina del levantamiento del velo.

En ocasiones, por ejemplo, se ha considerado que un ayuntamiento responde, directamente, por los dańos causados por una sociedad mercantil suya, argumentando que en derecho público actuar a través de una sociedad mercantil no es más que una técnica instrumental en la que la sociedad es un «ente filial puro y simple», que actúa externamente regulado por el derecho privado, pero que, internamente, pertenece a la Administración y está regido por esta. El hecho de que el ayuntamiento sea órgano de la sociedad municipal, y el alcalde, presidente de su Consejo - ha sostenido el Tribunal Supremoes «circunstancia más que suficiente para no considerar tercero o extraño al Ayuntamiento con respecto a la sociedad municipal demandada ${ }^{53}$.

En la misma línea, se ha considerado que era válida para interrumpir la prescripción la reclamación de deuda hecha a un ayuntamiento, en lugar de, como hubiera sido procedente, al Patronato municipal de la vivienda, que era el que había contratado con la empresa acreedora. En este caso, el Tribunal Supremo argumentó que la personalidad jurídica del Patronato no pasaba de ser un "recurso técnico-jurídico para agilizar y facilitar su gestión específica, pero sin que ello venga a representar, sobre todo en la práctica, que este Ente pueda ser considerado un auténtico penitus extranei respecto del Ayuntamiento

51 Se trata de la Ley de modificación de la Ley 22/1999, de creación del Ente de Derecho Público MINTRA (Madrid, Infraestructuras del Transporte).

52 Por ejemplo, la STS (Sala de lo Civil) de 26 de mayo de 1994, recurso 1353/1991; la SAN de 1 de diciembre de 2014, recurso 19/2013; y la STSJ del País Vasco de 5 de octubre de 2000. En el mismo sentido se pronuncian otras sentencias que pueden verse en el trabajo de M. A. Recuerda Girela (2012), págs. 693-699, al que me remito. STS (Sala de lo Civil) de 28 de mayo de 1984, RJ 1984\2800. 
matriz, como lo evidencia el que los principales miembros de la Junta rectora de aquél lo son por razón de los cargos desempeñados en éste» ${ }^{54}$.

En determinada ocasión, la identificación total entre la Administración (un ayuntamiento) y una fundación suya llegó hasta el punto de afirmar, con total falta de rigor, y sin otra argumentación que la de que la personalidad jurídica solo es un instrumento para conseguir una gestión más ágil, que la fundación no era más que un "simple órgano» en las relaciones internas con el ayuntamiento y que, en consecuencia, a los efectos de considerar que la fundación contaba con determinado medio material que resultaba exigible para obtener una subvención, era suficiente con que lo tuviera el ayuntamiento ${ }^{55}$.

Con mayor rigor, y sin necesidad de citar la doctrina del levantamiento del velo, el Tribunal Supremo ha sostenido que la personalidad y la capacidad de un ente instrumental de una Administración pública (un organismo autónomo municipal que gestionaba un teatro) «son solo operativas o instrumentales» y que ello no supone nada más que la existencia de una autonomía funcional, lo cual «no es suficiente para relevar al ayuntamiento de responsabilidad, aunque solo sea subsidiaria en las obligaciones contraídas por el teatro para cumplimiento de fines municipales». A esta conclusión llega el Tribunal Supremo después de haber argumentado que la Presidencia y la Vicepresidencia del Consejo de Administración correspondían, respectivamente, al alcalde y al concejal delegado de Cultura; que seis vocalías correspondían a concejales del ayuntamiento y tres se reservaban para representantes de las demás administraciones públicas; que las dos restantes se asignaban a puestos de trabajo también de designación municipal y, finalmente, que también formaba parte del Consejo el secretario interventor del ayuntamiento. Asimismo se dice que el ayuntamiento tenía que aprobar sus presupuestos y su plantilla laboral, que el teatro no disponía de más bienes que los afectados por el ayuntamiento y que su financiación también era del ayuntamiento ${ }^{56}$.

En sentido parecido, el Tribunal Superior de Justicia de Andalucía, haciendo aplicación expresa de la doctrina del levantamiento del velo, condenó a un ayuntamiento a pagar la deuda contraída por una sociedad mercantil municipal sobre la base de argumentar que: i) el administrador único era el ayuntamiento en la persona de su alcalde y (ii) que el ayuntamiento había hecho

54 STS (Sala de lo Contencioso-Administrativo) de 12 de junio de 1984, RJ 1984\3463.

55 STS (Sala de lo Contencioso-Administrativo) de 9 de junio de 1988, RJ 1988\5319, en cuyo fundamento de derecho tercero puede leerse lo siguiente: «en consecuencia la cocina del Ayuntamiento es cocina del Patronato y de las demás organizaciones — personificadas o no- dependientes de aquél».

56 STS de 22 de septiembre de 1995, RJ 199517495. 
desaparecer el activo de la sociedad mercantil impidiendo con ello el cobro de la cantidad que le había sido reconocida al demandante en sentencia firme. Se trata, pues, de un caso en el que en la jurisdicción contencioso-administrativa se ha aplicado la doctrina del levantamiento del velo en sentido estricto, es decir, entendiendo que dicha doctrina «autoriza a los Jueces a penetrar en el verdadero sustrato personal de las entidades y sociedades con el propósito de evitar que, en fraude de ley, hagan uso de la personalidad jurídica independiente para causar perjuicios a los intereses públicos o privados ${ }^{57}$.

\section{UNA PROPUESTA DE SOLUCIÓN AL PROBLEMA PLANTEADO}

A la luz de todo lo expuesto, podemos constatar que además de no existir un criterio unitario en la jurisprudencia respecto de la cuestión analizada, los argumentos para aplicar una regla (separación de responsabilidades) o la contraria (comunicación de responsabilidades) son de la más variada índole, ya que, mientras que en unos casos se aplica el criterio de la separación y no comunicabilidad de responsabilidades con base, únicamente, en el argumento formal de la existencia de un ente dotado de personalidad jurídica propia; en otros, por el contrario, se trasciende del dato de la personalidad jurídica, bien afirmando, sin más, que en el sector público no hay una distinción real de personalidades, bien penetrando en el sustrato real de las personas jurídicas de que se trate para constatar si, no obstante la diferenciación de personas jurídicas, existe identidad en sus órganos de gestión, o si la Administración matriz ejerce la tutela sobre la sociedad mercantil, o si dicha Administración la financia, o, incluso, si ha existido un comportamiento abusivo o fraudulento por parte de la Administración matriz.

En mi opinión, una cuestión de tanta importancia - teórica y práctica- no debería seguir manteniéndose en el estado de confusión que aquí ha quedado descrito. Una cosa es que la casuística tenga necesariamente que llevar a soluciones distintas, según los supuestos que se planteen, y otra muy diferente es que renunciemos por completo a sentar unas bases que nos permitan llegar a una solución mínimamente coherente sobre la cuestión planteada. Y, en general, que nos permitan comprender qué significado tiene, realmente, para el derecho público, la personalidad jurídica de las sociedades mercantiles públicas.

Para ello, creo que hay que partir del hecho de que existe una diferencia sustancial entre las sociedades mercantiles públicas y las privadas que radica en la razón de ser de las mercantiles públicas, es decir, en el porqué y para qué se crean.

57 STSJ de 21 de junio de 2010, recurso 852/2009. 
Las sociedades mercantiles públicas se crean para «huir» de la rigidez del derecho administrativo y buscar la flexibilidad en el derecho privado. El mecanismo que consiste en realizar actuaciones propias de la Administración a través de una sociedad mercantil es, como tantas veces han dicho los tribunales ${ }^{58}$, una técnica de organización administrativa consistente en crear un instrumento dotado formalmente de personalidad para gestionar — de forma especializada y con autonomía funcional- determinados asuntos de la competencia de las administraciones públicas. Siendo esto así, no es lógico que la consecuencia de crear este tipo de entidades sea que la personalidad jurídica diferenciada se levante como un muro ante el acreedor y excluya la responsabilidad de la Administración matriz, solo por el hecho de haber interpuesto una persona jurídica para llevar a cabo una actuación, que no deja de ser administrativa y de servicio al interés general, cuando lo único que se pretendía con ello era evitar los rigores del derecho administrativo.

Pero, sobre todo, la consecuencia no debería ser, en mi opinión, esa porque, tal y como ha quedado puesto de manifiesto, es el propio derecho administrativo el que, en un buen número de normas, identifica totalmente a la Administración matriz con sus entes instrumentales (cualquiera que sea la forma de personificación, pública o privada, de estos), negando, por tanto, que exista, realmente, una personalidad jurídica diferenciada en los entes instrumentales. Si son los propios tribunales y una pluralidad de normas de derecho administrativo los que equiparan la personalidad de la sociedad mercantil $y$, en general, de los entes instrumentales, a la de la Administración de la que depende, es lógico que el tercero que entabla una relación jurídica con este tipo de entes perciba la existencia de un único sujeto. Es decir, es lógico que el tercero identifique a la sociedad con su Administración, produciéndose, por tanto, en derecho público esa "confusión de esferas» que tiene lugar cuando «se desdibuja hacia fuera la separación entre la sociedad o el socio... y se crea la apariencia frente a terceros de que quien actúa es el socio" "59.

Es por ello por lo que considero que, en el ámbito del sector público, la regla debería ser que se pudiera exigir responsabilidad a la Administración matriz por las deudas de su ente instrumental, no de forma directa, porque

58 Conviene recordar que, en todas las sentencias que aquí se han citado, en las que los tribunales vienen a decir que la personalidad jurídica, en derecho público, no es más que una forma de agilizar la realización de actividades públicas, se da la circunstancia de que los tribunales no hacen diferencia alguna por el hecho de que el ente instrumental sea un organismo público o una sociedad privada.

59 C. Paz Ares (2012), «Las sociedades mercantiles», en A. Menéndez y A. Rojo (dirs.), Lecciones de Derecho Mercantil (pág. 357), vol. I, Cizur Menor: Aranzadi. 
ello supondría vaciar de todo significado a la personalidad jurídica, pero sí de forma subsidiaria cuando su ente instrumental no respondiera de sus deudas, mientras que la excepción debería ser la incomunicabilidad de responsabilidades $^{60}$.

Así, pues, en el supuesto de que una sociedad mercantil pública no responda de sus deudas, debería responder su Administración (u organismo público) matriz, como regla general, salvo que, analizadas las circunstancias concretas del caso, se pusiera de manifiesto la existencia de elementos suficientemente reveladores de que, en contra de la presunción de identidad sustancial de personalidades jurídicas que es propia y característica del sector público, existe realmente una separación o independencia de personalidades. Estas circunstancias podrían ser, por ejemplo, y entre otras, que se tratase de una sociedad en la que el capital no fuese íntegramente público; en la que no existiese financiación pública, sino que se financiara con su propia actividad en el mercado; en la que ninguna de sus actuaciones estuviera sometida a autorización previa ni a ningún otro mecanismo de control o tutela por parte de la Administración matriz; en la que las personas que integraran sus órganos de dirección o de gestión no fuesen las mismas personas titulares de los órganos de la Administración matriz, y, en general, cualquier otra circunstancia que, aislada o conjuntamente considerada, acreditase la existencia de una independencia real entre personalidades y patrimonios y no, simplemente, de una mera autonomía funcional.

Frente a lo que propongo cabría objetar que puede resultar incompatible con el derecho de la UE y, más concretamente, con la regla según la cual las sociedades mercantiles públicas deben actuar en igualdad de condiciones con las empresas privadas. Entiendo, sin embargo, que ello no sería obstáculo si se tienen en cuenta las dos circunstancias siguientes: en primer lugar, que esa regla resulta de aplicación solo a las sociedades mercantiles que, realmente, realicen actividades de mercado y en condiciones de mercado; en cuyo caso, por lo general, y precisamente por ello, estarían en la excepción al principio de la presunción de identidad sustancial de personalidades jurídicas que aquí he defendido. Y, en segundo lugar, porque también, en el ámbito del derecho de la UE, ha quedado puesto

60 L. Parejo ha llegado incluso a afirmar que «no existe legalmente velo alguno que levantar» y que «es la Ley la que directamente lo levanta, de suerte que la Administración matriz puede ser hecha responsable por las obligaciones incumplidas por sus organizaciones instrumentales», en (2006), «El juego de la técnica del levantamiento del velo en el caso de personas jurídicas creadas por o en mando de la Administración pública», Revista Jurídica de las Islas Baleares, 4, págs. 9-34. 
de manifiesto que la forma de personificación privada y la existencia de una personalidad jurídica diferenciada no son elementos suficientes para romper la unidad estructural de la Administración pública y de sus entidades dependientes. Baste recordar, a este respecto, las palabras del Tribunal de Justicia de la UE, en su conocida sentencia sobre el caso de la sociedad mercantil española SIEPSA ${ }^{61}$, en la que se trataba de determinar si la sociedad mercantil tenía o no la consideración de «organismo de Derecho público», a efectos de contratación:

[...] con independencia de si existe un mecanismo oficial de compensación de posibles pérdidas de SIEPSA, parece poco probable que ésta haya de soportar los riesgos económicos derivados de su actividad. En efecto, habida cuenta de que la realización de la misión de esta sociedad constituye un elemento fundamental de la política penitenciaria del Estado español, resulta verosímil que, como único accionista, dicho Estado tome todas las medidas necesarias al objeto de evitar una posible quiebra de SIEPSA.

Así, pues, frente a la posibilidad teórica de que las sociedades mercantiles públicas pueden entrar en concurso ${ }^{62}$, el Tribunal de Justicia de la UE viene a reconocer precisamente eso: que no es más que una posibilidad teórica. La realidad, por tanto, se impone a la ficción que, a menudo, crean las formas y los nombres en derecho.

61 STJUE de 16 de octubre de 2003, asunto C-283/00; apdo. 91.

62 La Ley 22/2003, Concursal, en su art. 1.3, excluye de la posibilidad de ser declaradas en concurso únicamente a las entidades que integran la organización territorial del Estado, a los organismos públicos y a los demás entes de derecho público, pero no a las entidades de derecho privado del sector público. 